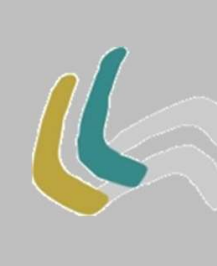

\title{
NAÇÃO, TERRENO DO DUPLO: A FUNÇÃO DO DUPLO NA MITOLOGIA DO ESTADO ABSOLUTISTA E DO ESTADO-NAÇÃO
}

\author{
THE NATION AS THE TERRITORY FOR THE DOUBLE: \\ THE USES OF THE DOUBLE IN THE MYTHOLOGIES OF \\ THE ABSOLUTIST STATE AND \\ THE NATION-STATE
}

\section{Breno Fernandes ${ }^{1}$ Universidade Federal da Bahia}

\begin{abstract}
Resumo: Este artigo faz uma leitura comparada entre a versão registrada por Plutarco do mito de Rômulo e Remo e a história das gêmeas Olanna e Kainene, personagens de Meio sol amarelo, romance da nigeriana Chimamanda Ngozi Adichie, que trata do surgimento e do esfacelamento de Biafra (atual Nigéria). O objetivo precípuo é sugerir que a figura do duplo, em ambas as narrativas, cumpre uma função mitológica comum relacionada à fundação tanto do Estado absolutista quanto do Estado-nação. A diferença que se observa tem a ver com o destino do duplo após o Estado ser fundado. No Estado absolutista, a presença do duplo humano torna-se empecilho, na medida em que o soberano passa a estabelecer uma relação de duplo com o próprio Estado, sendo necessário, portanto, o afastamento do duplo anterior, que por vezes se dá pela morte. Já no Estado-nação, que tem a fraternidade como um de seus pilares simbólicos, a presença do duplo é condição sine qua non não só para legitimar a fundação da nação, mas também para justificar sua continuidade.
\end{abstract}

Palavras-chave: Duplo; Estado; Nação; Rômulo e Remo; Chimamanda Ngozi Adichie.

1 Endereço eletrônico: brenofernandes@gmail.com. 
Abstract: This paper presents a comparative reading exercise between Plutarch's version for the myth of Romulus and Remus, and the story of the twins Olanna and Kainene, characters from Half of a yellow sun, a novel by Chimamanda Ngozie Adichie about the Biafran War. The main goal of this activity is to propose that the double, as seen within both narratives, has a mythological function related to the foundation of the Absolutist State, as well as the Nation State. But, depending on which type of state has been created, the double will have a specific destiny. In the Absolutist State, the presence of the human double soon becomes an obstacle, once the king needs to establish a similar relation to the state itself. Hence, the human double may be placed away or even murdered. On the other hand, as fraternity is one of the bedrocks of the Nation State, the preservation of the double is a sine qua non condition for both the foundation and the continuity of this form of state.

Keywords: Double; State; Nation; Romulus and Remus; Chimamanda Ngozi Adichie.

\section{INTRODUÇÃO}

Canclini (2008) escreveu que "a identidade é uma construção que se narra" (CANCLINI, 2008, p. 129). Barthes (2006), por sua vez, declarou que "o mito é uma linguagem" (BARTHES, 2006, p. 11). Em se somando as duas afirmativas, compreende-se por que os mitos há muito são uma das formas mais produtivas de se narrarem identidades: afinal de contas, eles são mais do que objetos, conceitos ou ideias; são todo um "sistema de comunicação" (BARTHES, 2006, p. 199; grifos nossos) - uma fonte infinita de narrativas. Por isso, aliás, nunca houve nenhuma tentativa exitosa de estabelecer uma versão oficial para as histórias mitológicas que a Antiguidade nos legou. Segundo Amarante (2015), “como um mito é, na verdade, um feixe de versões, cada mitógrafo o registra com determinadas particularidades" (AMARANTE, 2015, p. 52). Nesse contexto é que os mitos podem ser considerados um sistema de comunicação ou fontes narrativas.

Os mitos que produzem narrativas identitárias têm o propósito de inventar tradições, no dizer de Hobsbawm (1984). Essas tradições inventadas seriam instrumentos utilizados por "instituições políticas, movimentos ideológicos e grupos [...] sem antecessores" (HOBSBAWM, 1984, p. 15), a fim de forjar "uma continuidade histórica [...] através da criação de um passado antigo que extrapole 
a continuidade histórica real seja pela lenda [...] ou pela invenção" (HOBSBAWM, 1984, p. 15) - por meio de mitos, pode-se dizer. O objetivo de tal empresa, como é de se supor, é a legitimação do poder dos grupos dominantes, isto é, a legitimação de suas práticas e discursos.

Este artigo apresenta o duplo como tema mitológico que tem como uma de suas funções legitimar a forma do Estado, quer seja o Estado absolutista², quer seja o Estado-nação. O duplo foi escolhido em se considerando a arguição de Fusillo (2012) a respeito das profícuas reflexões antropológicas, sociológicas e psicológicas que têm sido extraídas desse tema ao longo da história. A principal ideia aqui defendida é a de que a figura do duplo, embora necessária para fundar ambas as formas de Estado, logo se torna um empecilho para o vicejar do Estado absolutista, ao passo que com o Estado-nação ocorre o contrário, isto é, a existência do duplo, mitologicamente, é quase condição sine qua non para a estabilidade dessa forma de Estado.

Para se comprovar a hipótese acima são feitos três movimentos. O primeiro ambiciona ler o mito dos irmãos Rômulo e Remo, identificando nele a relação entre o duplo e o Estado absolutista. Em seguida é feito o mesmo tipo de análise com as gêmeas Olanna e Kainene, personagens do aclamado romance histórico da escritora nigeriana Chimamanda Ngozi Adichie (1977), que trata da fundação e do fracasso de Biafra a partir de uma tentativa de secessão ocorrida na Nigéria, poucos anos depois da independência deste país em relação à colonização britânica. O que será observado, neste momento, é como a história trágica das gêmeas pode ser lida como alegoria da história trágica da nação biafrense. Por último, já nas considerações finais, ambas as narrativas analisadas

\footnotetext{
2 Utiliza-se aqui uma noção expandida de absolutismo. Embora, como doutrina política, o absolutismo possa ser rastreado até um momento específico da Idade Moderna europeia, o termo aparece neste artigo para tratar de qualquer situação, no espaço e no tempo, especialmente antes do advento do nacionalismo, em que o poder do rei ou chefe de Estado, na teoria ou na prática, de fato ou no nosso imaginário, pareça desconhecer limites, transformando a própria existência do Estado numa espécie de extensão ou obra do monarca.
} 
são justapostas e, ademais, sugerem-se outras histórias que podem vir a ser estudadas para de fato corroborar ou contestar a ideia de que o duplo serve proficuamente de tema mitológico ao Estado.

\section{RÔMULO E REMO}

Em introdução ao texto de Plutarco sobre a vida de Rômulo (Plu Rom.), Leão (2008) observa que, a despeito de o escritor grego apresentar algumas variações em relação à ascendência dos gêmeos Rômulo e Remo, ele reconhece que a maioria das fontes antigas aceitava a versão de que os irmãos nasceram do ventre de Reia Sílvia, filha de Numitor, herdeiro do trono de Alba Longa, reino fundado havia muito por Ascânio, filho de Eneias. Sucedeu que Numitor fora deposto por seu irmão, Amúlio, e este, precavendo-se contra uma futura vingança dos descendentes de Numitor, obrigou a que os bebês de Reia Sílvia fossem lançados no Tibre, o que de fato não ocorreu. Rômulo e Remo foram colocados em uma cesta que, arrastada docemente pela correnteza do rio, os levou para longe, onde primeiro foram resgatados e amamentados por uma loba e depois acolhidos por pastores.

Os dois jovens cresceram, e efetivamente afloraram "suas naturais qualidades de liderança" (LEÃO, 2008, p. 98). Ao obter conhecimento de sua progenitura, eles ajudaram o avô a recuperar o poder e logo partiram para fundar uma colônia de Alba Longa no local em que haviam sido retirados das águas. Porém - e aqui começa a parte do mito que mais nos interessa - ,

quando se preparavam para criar uma única cidade, surgiu entre eles um diferendo relativamente ao local. De facto, Rómulo fundou a chamada Roma Quadrada [...]; Remo, porém, escolheu antes uma zona sólida no Aventino, à qual deu o nome de Remória [...]" (Plu Rom. 9.4).

Segundo Plutarco, 
[a]cordaram entre si resolver a disputa através da observação das aves de bom augúrio. Tomaram então assento em lugares distintos e conta-se que Remo terá avistado seis abutres e Rómulo o dobro desse número. Alguns defendem que Remo avistou realmente as aves e que Rómulo mentiu, pois só ao chegar junto de Remo teria visto os doze abutres. [...] Quando Remo tomou conhecimento do ludíbrio, ficou enfurecido e, à medida que Rómulo ia traçando o sulco onde implantaria a cintura de muralhas, punha-se a desdenhar dos trabalhos e a criar entraves. Por último, ao saltar a vala foi atingido (segundo uns por Rómulo e segundo outros por Célere, um dos seus companheiros) e ali mesmo tombou morto. (Plu Rom. 9.5, 10.1-2)

Em nota de rodapé ${ }^{3}$, comentando o episódio do assassinato de Remo, Delfim F. Leão - que, na introdução ao texto, chamara o acontecimento de uma "querela fútil" (LEÃO, 2008, p. 98; grifos nossos) - observa que esse é dos elementos menos edificantes das lendas fundacionais, cuja função seria ajudar a caracterizar Rômulo (e, por extensão, o próprio povo romano) e, ademais, simbolizar o caráter inviolável das muralhas da cidade. É uma boa interpretação, mas, como é da natureza dos mitos serem fontes inesgotáveis de significações, apresenta-se a seguir uma proposta de leitura da história de Rômulo e Remo pela perspectiva do duplo, legitimada pelo clássico ensaio de Otto Rank, O duplo, no qual se reconhece que "encontramos [...] uma recorrente identificação do duplo com o irmão. [...] Esse, na maior parte das vezes, aparece como irmão gêmeo" (RANK, 1971, p. 75; tradução nossa ${ }^{4}$.

Atento à temática do heroísmo no mito de Rômulo e Remo, Meurant (2000) sugere que o contato com as águas do Tibre, a loba e a educação pastoril serviriam para enfatizar o caráter heroico dos gêmeos não tanto pelos aspectos de aventura ou de nobreza que esses elementos contêm, mas por conformarem um ambiente selvagem, que faz jus à premissa de que o herói, aquele com vocação para fundar

3 Cf. nota de rodapé n. 15 à p. 129 de: PLUTARCO. Vidas paralelas: Teseu e Rómulo. Coimbra: Centro de Estudos Clássicos e Humanísticos da Universidade de Coimbra, 2008. p. 96-173.

4 No original: "[...] we also find in our material that the double is often identified with the brother. [...] The appearance for the most part is a twin [...]" (RANK, 1971, p. 75). 
uma nova ordem (por vezes plasmada em um novo espaço), não tem mais nenhum contato com a velha esfera cultural. O intrigante, neste caso, é a existência do duplo, quando a realeza é, de modo geral, atribuída a um só indivíduo. Uma explicação possível, para Meurant (2000), é que, sendo o rei (o herói) um sujeito que "não pertence a nenhum grupo social, a nenhuma casta, a nenhuma comunidade" (MEURANT, 2000, p. 81; tradução nossa5); uma pessoa que se isola do resto dos homens devido a alguma ruptura radical; a geminilidade no caso em tela serviria como a ruptura-mor. Nas palavras de Meurant (2000),

a anomalia dos gêmeos leva em conta a tarefa atribuída a todo herói de uma civilização: a necessidade de inaugurar tempos novos após a dissolução da velha ordem. [...] Ao romper com a norma social (onde se espera apenas um, apareceram dois), os gêmeos são portanto os marginais [...] com atributos para enterrar o velho regime [...]. (MEURANT, 2000, p. 82; tradução nossa ${ }^{6}$ )

Como se verifica, a leitura de Meurant (2000) do mito de Rômulo e Remo aponta uma série de elementos úteis à consolidação de uma identidade singular para a nação romana, servindo de ilustração ao processo que Canclini (2008) explica ser necessário para se criar narrativamente a identidade de qualquer grupo que se reconheça como um povo. Diz o antropólogo argentino:

Estabelecem-se acontecimentos fundadores, quase sempre relacionados à apropriação de um território por um povo ou à independência obtida através do enfrentamento dos estrangeiros. Vão se somando as façanhas em que os habitantes defendem esse território, ordenam seus conflitos e estabelecem os modos legítimos de convivência, a fim de se diferenciarem dos outros. (CANCLINI, 2008, p. 129; grifos nossos)

5 No original: “[...] n'appartient à aucun groupe social, à aucune caste, à aucune communauté [...]" (MEURANT, 2000, p. 81).

6 No original: “[...] l'anomalie gémellaire considérée sous cet angle prend en compte la tâche impartie à tous héros civilisateur: le nécessité d'inaugurer des temps nouveaux après dissolution d'un ordre antérieur [...]. En rupture avec la norme sociale (ils sont nés deux là où un seul était attendu), les jumeaux sont donc des marginaux [...] compétents pour sonner le glas d'un régime périmé [...]" (MEURANT, 2000, p. 82). 
Ao mesmo tempo, ao falar em independência e façanhas, Canclini (2008) acaba fazendo eco às ideias de Meurant (2000) sobre a temática do heroísmo como condição sine qua non dos mitos de origem. Um fator que, no caso de Roma, leva invariavelmente à seguinte pergunta: como interpretar o assassinato de Remo, em uma querela fútil, sem que isso manche a grandeza, o heroísmo de Rômulo? Algumas teses a respeito do duplo nos ajudam a responder à questão.

Freud (2010), em seu estudo sobre o inquietante (Das Unheimliche), define esse sentimento como "aquela espécie de coisa assustadora que remonta ao que é há muito conhecido, ao bastante familiar" (FREUD, 2010, p. 249), e reconhece no duplo uma das fontes de inquietação, "em todas as suas gradações e desenvolvimentos" (FREUD, 2010, p. 263). Essa hipótese também aparece em Meurant (2000), quem assevera que, na Antiguidade, embora a leitura positiva do nascimento de gêmeos fosse possível7, de modo geral este era um acontecimento permeado de mal-estar (malaise). Por isso, aliás, explica Meurant (2000), não é rara, nos mitos da época, a existência de gêmeos com pais diferentes, "para distinguir desde cedo, in utero, aquilo que a natureza confunde maliciosamente" (MEURANT, 2000, p. 63; tradução nossa ${ }^{8}$ ). Mas este não era o caso de Rômulo e Remo, o que significa dizer que não havia atenuantes para o mal-estar suscitado por sua geminilidade. A morte, com efeito, parece ter servido a essa função: “[...] eliminando seu irmão, Rômulo traz de volta a norma tranquilizadora da unidade, dissipa o clima ambíguo que perpassava o local que veria se erguerem as muralhas de Roma" (MEURANT, 2000, p. 87; tradução

\footnotetext{
7 Tal reconhecimento se encontra no trecho em que Meurant (2000) afirma que "o rei é garantia de proteção e de prosperidade para seu povo, [...] qualidades que também são associadas aos gêmeos, se eles forem vistos positivamente" (MEURANT, 2000, p. 81; tradução nossa). No original: "[...] le roi est gage de protection et de prospérité pour son peuple [...], toutes qualités toujours propres aux jumeaux" (MEURANT, 2000, p. 81).

8 No original: "[...] por distinguer au plus tôt, in utero, ceux que la nature confond malicieusement" (MEURANT, 2000, p. 63).
} 
nossa ${ }^{9}$. Dito de outro modo, o aspecto negativo do fratricídio seria compensado pelo fim da inquietação - sem se deixar de lado, é claro, a interpretação que considera que, ao matar o irmão por este ter cruzado os limites impostos pelo líder, Rômulo estaria pondo a lei acima dos afetos e vínculos sanguíneos, punindo com punho de ferro a transgressão, independente de quem a cometera, num ato muito parecido ao do Creonte de Sófocles (Sof. Ant.), que Holanda (1995) consagraria como o tipo civilizado por excelência.

É preciso considerar, entretanto, que a primeira forma política de Roma foi a monarquia, regime em que há espaço para um líder somente, cujas vontades se transformam em ordem soberanamente, isto é, sem nenhuma possibilidade de controle - pelo menos assim sucede em nosso imaginário, em relação aos velhos reinos. Havemos de convir que este é um ambiente inabitável para o duplo, notadamente se tomamos a sério as considerações de Freud (2010), de que o duplo pode ser compreendido como "uma instância especial" (FREUD, 2010, p. 264), projetada para fora do Eu como algo estranho, inquietante, notadamente, por servir à auto-observação e à autocrítica do Eu. Ao duplo, ademais, se apegaria, segundo Freud (2010), “todas as tendências do Eu que não puderam se impor devido a circunstâncias desfavoráveis" (FREUD, 2010, p. 264). Nesse contexto, é compreensível que o assassínio de Remo seja um ato de instauração do poder absoluto, libertando Rômulo das amarras psíquicas de seu duplo e, politicamente, vaticinando aquilo de que fala Hermes Orígenes Duarte Vieira, tradutor e comentador da Guerra civil de Lucano, em nota de rodapé relacionada ao episódio fratricida (Luc. B.C. 1, 95): a de que o poder não se compartilha, nem mesmo com os irmãos ${ }^{10}$.

\footnotetext{
9 No original: “[...] qu'en supprimant son frère Romulus dissipe, par le fait de ramener la gémellité à la norme rassurante de l'unité, le climat équivoque où baignaient les lieux qui verront se dresser les remparts de Rome" (MEURANT, 2000, p. 87).

10 Cf. nota de rodapé n. 35, à p. 32 de: LUCANO. Guerra civil - livro I. João Pessoa: Ideia, 2018.
} 
De certo modo, o próprio Estado, pensado como materialização da vontade do rei, acaba se tornando uma espécie de duplo do rei, como sugere a máxima de Luís XIV, o Rei Sol: O Estado sou eu. Nessa relação, o duplo de carne e osso precisa ser eliminado, o que pode se dar pelo confinamento, pelo exílio ou mesmo pela morte - a sina de Remo. No Estado-nação, como se verá a seguir, é justo o contrário que se espera do duplo.

\section{OLANNA E KAINENE}

O fim da colonização do continente africano, ao longo da segunda metade do século $X X$, foi, para muitos países, um período de grave instabilidade. Como é sabido largamente, isso em parte se deveu a que os colonizadores reuniram povos de culturas diferentes sob a égide do Estado-nação, ou de um arremedo dessa instituição, uma forma política que demandava que fosse forçosamente descartada uma das identidades-mestras dos sujeitos colonizados - aquela que lhes dava senso de pertencimento a um grupo - , de modo a ser substituída por uma identidade nacional. Anderson (2008) nos recorda de que a nação "é imaginada como uma comunidade porque, independentemente da desigualdade e da exploração efetivas que possam existir dentro dela, [...] sempre é concebida como uma profunda camaradagem horizontal" (ANDERSON, 2008, p. 34; grifos nossos), um construto que, vale citar Canclini (2008) novamente, se dá por meio da repetição de narrativas que confirmem a origem comum e a singularidade das pessoas que conformam a nação.

Para exemplificar como essas repetições ocorrem, Canclini (2008) menciona "[o]s livros escolares e os museus, assim como os rituais cívicos e os discursos políticos" (CANCLINI, 2008, p. 129): alguns dos dispositivos repetidores dos mitos identitários. Sucedeu que, durante o período de colonização da África, por vezes as metrópoles incitaram a competição, a 
inimizade ou mesmo o ódio entre os povos que haviam reunido sob uma mesma unidade administrativa, sob um protoestado-nação. Nesse contexto, no imediato pós-independência, todo o aparato identitário nacional era por demais recente e conectado a uma vivência pavorosa de exploração, desprezo e jugo cruento, da parte tanto dos colonizadores quanto, não raro, das etnias colonizadas a que eles davam preferência. $\mathrm{O}$ resultado disso foi - em alguns países, ainda tem sido o conflito interétnico, ameaça potencial à existência do Estado-nação, inclusive no que concerne à criação de narrativas identitárias contrárias às da comunidade nacional.

O caso apresentado neste artigo é o da Nigéria, que, sem ter conseguido engendrar uma narrativa nacional que sopesasse as rivalidades entre seus principais grupos étnicos, enfrentou uma guerra de secessão, a Guerra de Biafra (1967-1970), quando o lado leste do sul do país quis conformar um Estado-nação etnicamente mais homogêneo. Todos os dados históricos que se encontram a seguir foram tirados de Forsyth (1977), quem cobriu o conflito do lado derrotado, o lado biafrense.

Segundo Forsyth (1977), em 1960, quando a Inglaterra se retirou da Nigéria, o país se dividia em três regiões autônomas: o Norte, comandado pelos haussás e fulânis, que se irmanavam na religião muçulmana. O Oeste, onde predominavam os iorubás, e o Leste, de maioria ibo. Pouco depois, surgiria ainda uma quarta região, o Meio-Oeste, zona de relativo equilíbrio entre ibos e iorubás. A Nigéria era, portanto, uma federação, com um chefe de governo central que, na prática, rivalizava com os chefes de governo regionais, em especial os do Norte. Nessa região, a mais interiorizada do país, os ingleses prontamente implantaram a colonização por meio do chamado indirect rule, um domínio indireto, baseado na cooptação de líderes locais, com vistas a que estes atendessem aos interesses da metrópole. Destarte, os chefes do Norte conseguiram preservar as estruturas de poder e os modos de vida pré-coloniais 
de modo relativamente mais eficaz do que as regiões do sul, onde ficava a zona portuária e administrativa do país, o que por si só já proporcionava contatos culturais mais frequentes. Exemplo disso foi o grande afluxo que ocorreu, nas áreas do sul, de imigrantes advindos da metrópole, principalmente burocratas e missionários, estes últimos funcionando como agentes de uma política educacional massificada e europeizada. Não à toa, no ano da independência, “embora o norte contasse com mais da metade da população da Nigéria, de 50 milhões de habitantes, tinha apenas 41 escolas secundárias, contra as 842 do sul" (FORSYTH, 1977, p 19). Os ibos, principalmente, tornaram-se os maiores beneficiários das demandas por gente especializada no novo Estado-nação, sendo que, historicamente, ao que tudo indica, eram considerados o povo mais "atrasado" - com as devidas aspas, que Forsyth (1977) esqueceu de pôr ao usar este termo. Consequentemente, tornaram-se os mais interessados em "modernizar" (de novo, com as devidas aspas) o país, ameaçando a sobrevivência das estruturas de poder do Norte.

Em meados do ano de 1966, houve uma tentativa de golpe de Estado, comandada por "oficiais subalternos do Exército de origem nortista" (FORSYTH, 1977, p. 53), visando sobretudo à defenestração da plutocracia corrupta que governava o país. O major-general Johnson Aguiyi-Ironsi, um ibo educado no Norte, coordenou um contragolpe e, graças ao prestígio que tinha dentro e fora do país, foi instado a permanecer no poder, tanto para lidar com a corrupção e a instabilidade política que enfraqueciam a Nigéria quanto para formar um governo de coalizão entre as três principais etnias. O que funcionou somente até o Norte se sentir ameaçado pelos discursos em prol da unificação nigeriana e então orquestrar um golpe que matou Ironsi e os administradores escolhidos por ele para as regiões Oeste e Meio-Oeste, permitindo que Yakubu Gowon, um coronel nortista, se declarasse o novo chefe de governo. Sucedeu que, no Leste, o coronel Chukwuemeka Ojukwu não reconheceu a legitimidade do governo 
Gowon, defendendo a manutenção da linha sucessória, que dava ao general-debrigada Ogundipe o direito de governar ou demandava que um novo líder fosse escolhido pelo Conselho Militar Supremo, órgão decisório máximo do regime vigente, do qual o próprio Ojukwu fazia parte, mas não o coronel Gowon. Dessa desavença surgiram as condições para que, em 30 de maio de 1967, o Leste declarasse que não mais fazia parte da Nigéria, era agora um novo país: Biafra.

O final dessa história todos sabemos. Ficou estampado em imagens que foram parar nas capas de revistas de circulação internacional, fotografias icônicas que circulam e causam consternação até os dias de hoje. É que, para além das baixas militares e civis causadas por ataques terrestres e aéreos, estima-se que dois milhões de biafrenses - de um total de 14 milhões - tenham perecido de fome, por conta de um longo bloqueio de alimentos estabelecido pelo governo nigeriano e que contou com a conivência da comunidade internacional. Por isso é que um dos narradores do pungente Meio sol amarelo, romance histórico de Chimamanda Ngozi Adichie sobre a Guerra de Biafra, decide batizar o livro que deseja escrever para relatar o horror que seus compatriotas viveram com o título de $O$ mundo estava calado quando nós morremos.

Feita essa breve contextualização histórica, é hora de nos debruçarmos sobre o romance de Adichie (2008), pois nele se encontram elementos que permitem compreender o papel político que a figura do duplo pode ter na mitologia do Estado-nação. Meio sol amarelo conta com um narrador onisciente que se alterna em acompanhar o ponto de vista de três personagens: (1) Ugwu, um adolescente campesino que vai para Nsukka trabalhar como criado de um professor universitário e ativista do nacionalismo biafrense, Odenigbo; (2) Olanna, uma mulher de família rica, educada na Inglaterra, namorada de Odenigbo, que, para desgosto dos pais, recusa as investidas de um político e suas ofertas de emprego nepotistas, optando por tornar-se professora na Universidade de Nsukka; (3) e Richard, um inglês que foi para a Nigéria movido por algo entre 
o impulso e a curiosidade de conhecer de perto a cultura ibo, com a qual ele travou contato em sua terra natal e pela qual se apaixonou. Para o núcleo principal ficar completo, falta apenas mencionar Kainene, a gêmea bivitelina de Olanna, namorada de Richard e responsável por tocar os negócios da família, embora isso mexa um pouco com os brios machistas do pai.

O fato de Olanna e Kainene serem bivitelinas remete a uma das funções que Meurant (2000) apontou como úteis à diferenciação de gêmeos: o rompimento da unidade da célula univitelina "abre a porta a toda uma série de traços distintivos, permitindo classificá-los no plano do caráter, da força, do talento e da competência" (MEURANT, 2000, p. 63; tradução nossa11). Não à toa, na primeira cena em que aparecem juntas, o que fica em evidência são suas personalidades diferentes, metonimizadas em suas escolhas profissionais, bem como na lembrança de Olanna de que "Kainene sempre fora uma criança retraída, depois uma adolescente enfezada, e muitas vezes desagradável, a filha que, por nunca ter tentado agradar aos pais, deixava a tarefa toda para Olanna" (ADICHIE, 2008, p. 49). Com todas essas discrepâncias, não é de se estranhar que elas não sejam mais próximas uma da outra.

Adiante, na cena em que Richard conhece Kainene e descobre que ela tem uma gêmea, Kainene nos revela outro traço distintivo entre as irmãs - a sina que foi legada a cada uma pelo batismo: “O nome dela é o poético Ouro de Deus, e o meu é mais prático: Vamos esperar e ver o que mais Deus vai nos trazer." (ADICHIE, 2008 , p. 73). Apesar de a praticidade ser um trunfo em meio a uma guerra, como somos levados a acreditar vendo o modo como Kainene se porta ao longo do conflito, fazendo negócios com as partes envolvidas, mas também prestando ajuda humanitária; apesar disso, é a poética Olanna, que, ainda nos tempos de paz, apesar de ter nojo dos ovos de barata que vê na cozinha da tia pobre, faz

11 No original: "[...] ouvre la porte à totue une série de traits distinctifs permettant de les typer sur le plan du caractère, de la force, des talents ou des compétences" (MEURANT, 2000, p. 63). 
questão de não recusar a comida que lhe é oferecida, para não ferir as tradições populares; que vai acompanhar a intelligentsia de Nsukka na defesa de uma Biafra independente; que vai ficar emocionalmente destroçada com os horrores da guerra; é ela, a poética Olanna, que, depois de ser salva por Kainene, sobrevive à guerra, enquanto a irmã desaparece inesperadamente, durante uma viagem de carro que não oferecia maiores riscos do que ela vinha enfrentando. Essa talvez seja a grande reviravolta do romance, instauradora de um anticlímax pesado, que faz o leitor sofrer com Olanna a ausência mesma de um corpo para velar. E é também uma alegoria sobre a relação entre o duplo e o Estado-nação pelo seguinte motivo:

Dentre os termos e expressões dos quais Anderson (2008) se vale para tratar dos laços entre os membros da comunidade nação, para além de "profunda camaradagem horizontal" (ANDERSON, 2008, p. 34; grifos nossos), também se registra "fraternidade" (ANDERSON, 2008, p. 34; grifos nossos). É uma palavra condizente com o ideário do Estado-nação, pensado historicamente. Afinal de contas, a Revolução Francesa (1789), o acontecimento que, como explica Hobsbawm (2010), marcou o fim da hegemonia do Estado absolutista e o início da hegemonia do Estado-nação, para além da liberté e da égalité, também apregoou a fraternité. Com a Revolução Francesa, a associação entre "povo" e "nação" teve efeitos poderosos. De início, serviu para que a burguesia revolucionária francesa justificasse sua luta contra o monopólio de privilégios políticos mantido pela nobreza; para que angariasse o apoio de classes economicamente inferiores à causa. No entanto essa associação se tornou algo maior, constituiu ideia autônoma - o nacionalismo - , utilizada por diferentes grupos, por razões diversas. O nacionalismo serviu, por exemplo, às elites coloniais para que legitimassem sua independência, como sucedeu na Nigéria e em Biafra também. 
A despeito das críticas e modificações que vêm enfrentando atualmente, o nacionalismo, em linhas gerais, é uma ideologia que produz identidades com base na caracterização discursiva de um conjunto de práticas particularíssimas e exclusivas de um povo que ocupa um território bem delimitado espacialmente. Nesse contexto, o Estado-nação se torna a síntese, ou a materialização, ou a forma jurídica das sociedades que compartilham essa ideologia. E, acima de tudo, se torna uma instituição que, no imaginário das pessoas, se aproxima bastante da figura do genitor - seja o pai, vislumbrado na etimologia da palavra pátria, cujo equivalente em inglês, fatherland, pode ser encontrado na letra dos hinos tanto da Nigéria $^{12}$ quanto de Biafra ${ }^{13}$; seja a mãe, evocada explicitamente, por exemplo, no hino nacional brasileiro: Dos filhos deste solo és mãe gentil...

É recorrente a ocorrência de analogias com a família nos discursos que legitimam o Estado-nação. Este, o pai ou mãe; os nacionais, os filhos, irmãos entre si. Meio sol amarelo soma-se a tais discursos, na medida em que alegoriza a história de Biafra valendo-se de gêmeas não idênticas - o limiar entre a igualdade e a diferença a partir de uma origem comum, um lugar simbólico que é possível que todos nós já tenhamos visitado alguma vez na vida, ao identificar no outro, tão diferente em aparência ou em personalidade, um igual por causa da nacionalidade (quer dizer, das práticas que a compõem) ${ }^{14}$. No romance de Adichie (2008), a fraternidade de Olanna e Kainene, nem sempre dispostas a

\footnotetext{
12 "Arise, o compatriots/ Nigeria's call obey/ to serve our fatherland / with love and strength and faith". Em tradução nossa: "Levantem-se, ó, compatriotas/ ao chamado da Nigéria por obediência/ para servir nossa pátria/ com amor, e força, e fé." Confira a letra completa em: $<$ https://en.wikipedia.org/wiki/Arise,_O_Compatriots>. Acesso em: 30 jul. 2018.

13 "Hail to Biafra, consecrated nation,/ O fatherland, this be our solemn pledge". Em tradução nossa: "Salve, Biafra, nação consagrada,/ Ó, pátria, que esta seja nossa súplica solene". Confira a letra completa em: <https://en.wikipedia.org/wiki/Land_of_the_Rising_Sun_(anthem)>. Acesso em: 30 jul. 2018.

14 Mário de Andrade (1987) escreveu um poema sobre esse inquietante nacionalista: "Não vê que me lembrei que lá no norte, meu Deus! muito longe de mim/ Na escuridão ativa da noite que caiu,/ Um homem pálido, magro de cabelo escorrendo nos olhos/ Depois de fazer uma pele com a borracha do dia,/ Faz pouco se deitou, está dormindo./ Esse homem é brasileiro que nem eu..." (ANDRADE, 1987, p. 203).
} 
conviver ou a convergir, mas jamais estabelecendo uma hierarquia entre si, é, de certo modo, pedagógica quanto àquilo em que se baseia a vida em uma comunidade nacional: no momento de sufoco, irmãos precisam se apoiar, independentemente de seus atritos. É a lei do sangue e é a lei da nação. Por isso, a morte de Kainene, quando a guerra já se aproxima do final, é um acontecimento simbólico, que representa também o esfacelamento de Biafra. O duplo, na mitologia do Estado-nação, é quem materializa e atesta a existência da pátria ou da mátria, como diria Caetano Veloso. É o espelho que ativa a identidade e faz lembrar da origem, da filiação comum. Quando ele se ausenta, não se perde somente um irmão, mas a família inteira.

\section{CONSIDERAÇÕES FINAIS}

Um dos motivos pelos quais o duplo está presente há tanto tempo na história da humanidade talvez seja porque ele é capaz de bem ilustrar o inquietante jogo de igualdades e de diferenças pelo qual se constrói tanto o eu quanto o nós, tendo sempre o(s) outro(s) como base. No que concerne a esse nós, significando uma forma de convívio social, o que se tentou identificar aqui foi como o duplo pode desempenhar uma função político-pedagógica na mitologia do Estado. Sucede que, se se trata de um Estado absolutista, o duplo, sendo importante para sua fundação, com cedo se torna um empecilho, o que demanda seu desaparecimento, por vezes pela morte. Mas, no Estado-nação, o desaparecimento do duplo tem efeito contrário: transforma-se em entrave para a própria continuidade da instituição. Dito de forma sucinta e esquemática, temos que, no Estado absolutista, o duplo é uma força desagregadora, que, podendo ser um elemento fundador, logo deve se extinguir para se alcançar a ordem. Já no Estadonação, o duplo é uma força agregadora, que não só deve ser um elemento fundador, como também não deve se extinguir para que a ordem seja mantida. Nesse 
contexto, parece razoável afirmar, à guisa de conclusão, que a nação é o terreno do duplo por excelência.

Os casos de Rômulo e Remo e de Olanna e Kainene são ilustrações dessa hipótese, e não são as únicas. A narrativa do duplo que precisa sair de cena para que o Estado absolutista não entre em colapso pode também ser encontrada em outras histórias, seja em outros mitos da Antiguidade greco-latina, como na história de Acrísio e Preto; nas narrativas bíblicas, a exemplo de Esaú e Jacó; e em romances historicamente não tão longevos, feito O homem da máscara de ferro, de Alexandre Dumas. Todos elas, tramas de geminilidade, poder e Estado.

Quanto à alegoria do duplo relacionada ao Estado-nação, que se registre aqui pelo menos um outro romance que se vale da estratégia utilizada por Adichie (2008): Esaú e Jacó, de Machado de Assis. Nele, conforme se lê em Gledson (2003), os gêmeos Pedro e Paulo parecem metonimizar a disputa entre monarquistas (não absolutistas) e republicanos que marcou o Brasil na passagem do século XIX para o século XX.

Todas essas narrativas, que não entraram na presente análise porque decerto extrapolariam o intuito deste artigo - ser pequeno e sugestivo, mais do que vaticinador - , são mencionadas com a expectativa de que inspirem aqueles que, porventura tendo chegado até este ponto, tenham se interessado pelo tema da função do duplo na mitologia do Estado e queiram explorá-lo, seja para corroborar ou para contestar as ideias que acabamos de apresentar.

\section{REFERÊNCIAS}

ADICHIE, Chimamanda Ngozi. Meio sol amarelo. Tradução de Beth Vieira. São Paulo: Companhia das Letras, 2008.

ANDRADE, Mário de. Dois poemas acreanos. In: Poesias completas. Belo Horizonte: Itatiaia; São Paulo: EDUSP, 1987. p. 203-206.

AMARANTE, José. Latinütas: leitura de textos em língua latina. Fábulas mitológicas e esópicas, epigramas, epístolas. Salvador: EDUFBA, 2015. 
ANDERSON, Benedict. Comunidades imaginadas: reflexões sobre a origem e a difusão do nacionalismo. Tradução de Denise Bottman. São Paulo: Companhia das Letras, 2008.

BARTHES, Roland. Mitologias. Tradução de Rita Buongermino, Pedro de Souza e Rejane Janowitzer. 2. ed. Rio de Janeiro: DIFEL, 2006.

CANCLINI, Néstor García. As identidades como espetáculo multimídia. In: Consumidores e cidadãos: conflitos multiculturais da globalização. Tradução de Maurício Santana Dias. 7. ed. Rio de Janeiro: Editora UFRJ, 2008. p. 129-139.

FREUD, Sigmund. O Inquietante. In: Obras completas, v. 14. Tradução de Paulo César de Souza. São Paulo: Companhia das Letras, 2010. p. 247-283.

FORSYTH, Frederick. A história de Biafra: o nascimento do mito africano. Tradução e A. B. Pinheiro de Lemos. 7. ed. Rio de Janeiro: Record, 1977.

FUSILLO, Massimo. L'altro e lo stesso: teoria e storia del doppio. 2. ed. Modena: Mucchi Editore, 2012. p. 24-42.

GLEDSON, John. Machado de Assis: ficção e história. Tradução de Sônia Coutinho. São Paulo: Paz e Terra, 2003.

HOBSBAWM, Eric J. A era das revoluções, 1789-1848. Tradução de Maria Tereza Teixeira e Marcos Penchel. 25. ed. São Paulo: Paz e Terra, 2010.

HOBSBAWM, Eric J. Introdução: a invenção das tradições. In: HOBSBAWM, Eric; RANGER, Terence (Org.). A invenção das tradições. Tradução de Celina Cardim Cavalcante. Rio de Janeiro: Paz e Terra, 1984. p. 9-23.

HOLANDA, Sérgio Buarque de. Raízes do Brasil. 26. ed. São Paulo: Companhia das Letras, 1995.

LEÃO, Delfim F. Introdução. In: PLUTARCO. Vidas paralelas: Teseu e Rómulo. Tradução de Delfim F. Leão e Maria do Céu Fialho. Coimbra: Centro de Estudos Clássicos e Humanísticos da Universidade de Coimbra, 2008. p. 97-108.

LUCANO. Guerra civil - livro I. Tradução de Hermes Orígenes Duarte Vieira. João Pessoa: Ideia, 2018.

MEURANT, Alain. Romulus, jumeau et roi: aux fondements du modèle héroïque. Revue belge de philologie et d'historie, t. 78, fasc. 1, p. 61-88, 2000.

PLUTARCO. Vida de Rómulo. In: Vidas paralelas: Teseu e Rómulo. Tradução de Delfim F. Leão e Maria do Céu Fialho. Coimbra: Centro de Estudos Clássicos e Humanísticos da Universidade de Coimbra, 2008. p. 96-173.

RANK, Otto. The double: a psychoanalytic study. Tradução de Harry Tucker Jr. Chapel Hill: The University of North Carolina Press, 1971.

Nota do editor:

Artigo submetido para avaliação em: 10 de março de 2021.

Aprovado em sistema duplo cego em: 13 de julho de 2021. 